\title{
ULTRA-VIOLET REFLECTING POWER OF ALUMINUM AND SEVERAL OTHER METALS
}

\author{
By W. W. Coblentz and R. Stair
}

\section{ABSTRACT}

In this paper data are presented on the ultra-violet reflecting power of alumioum, duralumin, tin, and rhodium.

The data on aluminum are of special interest in connection with the use of this metal in reflectors of therapeutic lamps. The results of this investigation show that the ultra-violet reflecting power of aluminum compares favorably with that of chromium (previous investigation, RP39), increasing in reflecting power from about 50 per cent at $300 \mathrm{~m} \mu$ to 75 per cent at $550 \mathrm{~m} \mu$. In the visible spectrum, the reflectivity is higher than that of chromium.

The ultra-violet spectral reflection of duralumin is similar to that of aluminum. Tin has a fairly high reflecting power and may be useful in certain types of echelette gratings. Mirrors of rhodium are best prepared by cathode sputtering. The reflectivity observed on a polished regulus of rhodium increases from about 30 per cent at $260 \mathrm{~m} \mu$ to 45 per cent at $365 \mathrm{~m} \mu$.

\section{CONTENTS}

I. Introduction

II. Reflectivity data. 190

1. Aluminum

2. Duralumin $\ldots$

3. Rhodium ... 191

4. Tin

III. Summary

192

\section{INTRODUCTION}

The primary object of this paper is to present data on the ultraviolet reflecting power of aluminum, which is being extensively used for reflectors in connection with sources of ultra-violet radiation. For this purpose the sheet of aluminum is "spun" into a bowl-shaped mirror, which process gives a much higher polish than is possible by the regular methods of polishing on a wax surface.

Recently there have been frequent inquiries for information regarding the reflecting power of this type of surface.

In view of the fact that most lamps used for therapeutic purposes are provided with reflectors, it is relevant to emphasize that the mirror acts solely to reflect more or less perfectly the rays incident upon it and does not itself contribute anything additional to that radiation. In fact, since the reflector absorbs more of the short-wave length ultra-violet than of the visible and the infra-red rays, especially when the powdered metal (for example, aluminum) is applied with a lacquer, the total amount of ultra-violet radiation in proportion to the visible and the infra-red rays is relatively lower in the reflected rays than in those that proceed directly from the source. The reflector, placed back of the source, simply increases, therefore, the total amount of radiation of all wave lengths falling on an object placed in front of the lamp. The reflector can not supply ultra-violet wave lengths that may be lacking in the source, and after it becomes covered with smoke 
from the arc the amount of reflected radiation is, of course, greatly reduced.

Likewise windows or filters used in front of the source of ultraviolet, whether it be the sun or the mercury or the carbon arc, emit no ultra-violet wave lengths themselves, but always reduce the intensity of the rays that are present. The same is true of lacquers used in applying the powdered metal for a reflecting surface. Linseed oil and cellulose lacquer are highly opaque to ultra-violet radiation of wave lengths shorter than $350 \mathrm{~m} \mu$. $^{1}$

\section{REFLECTIVITY DATA}

The apparatus and procedure used in the present investigation vere described in a previous paper ${ }^{2}$ to which reference may be made for details regarding such matters.

The metals examined were in the massive form, cast into blocks or rolled into flat sheets, as used commercially, thus differing from films deposited on glass by cathode sputtering.

\section{ALUMINUM}

Two kinds of material were investigated: (1) The commercial rolled sheets (2 to $3 \mathrm{~mm}$ in thickness) without additional polish, and (2) a cast block of the pure material (99.999 per cent pure) prepared by the metallurgy division of this bureau by melting and solidifying in a vacuum. The surface of the cast material was somewhat porous. It was highly polished by S. Epstein, by a special buffing process, but vas not optically flat.

As shown in Figure 1, the spectral reflection of the polished sample of cast aluminum is relatively high, amounting to almost 50 per cent at $300 \mathrm{~m} \mu$ and gradually rising to 75 per cent at $550 \mathrm{~m} \mu$. These values would probably be 5 to 10 per cent higher if scattering of light at the surface of the metal were eliminated. The minimum reflectivity of the region of $275 \mathrm{~m} \mu$ is noted, since it appears in other metals. ${ }^{3}$

The general trend of the spectral reflection curve of the rolled material is similar to that of the cast block, and it is assumed would coincide with that of the highly polished surface, if scattering of the light were eliminated.

The ultra-violet reflecting power of aluminum compares favorably with that of chromium and provides an inexpensive reflector where a correctly figured highly polished surface is not required.

It is to be noted that any reflector used with the carbon arc may have its reflecting power greatly reduced by deposits of oxides.

Using cathodically deposited films of aluminum on glass, Hulburt ${ }^{4}$ obtained a reflectivity of above 60 per cent at $300 \mathrm{~m} \mu$ which was higher than found for any of the other metals examined except silicon.

In view of the fact that surfaces of substances, especially metals, are subject to corrosion, and that ultra-violet light accelerates the disintegration of the metal surface, ${ }^{5}$ it was considered important to determine the effect of ultra-violet light upon one of the samples,

1 Stutz, jr., Franklin Inst., 200, pp. 87, 89, 202; 1926.

2 Coblentz and Stair, B. S. Jour. Research (RP39), 2, p. 343; 1929.

3 Coblentz and Stair, B. S. Jour. Research (RP39), 2, p. 342; 1929.

4 E. O. Hulburt, The Reflecting Power of Metals in the Ultra-Violet Region of the Spectrum, Astrophys. J., 42, p. 205; 1915.

' Coblentz and Hughes, Science, 60, p. 64; B. S. Sci. Paper No. 493, 19, p. 577; 1924. 
since aluminum is widely used as a reflecting surface in therapeutic lamps. For this purpose the sample of rolled aluminum was exposed to the total radiation of a 110 -volt, d. c. quartz mercury arc lamp, at a distance of $15 \mathrm{~cm}$ for 30 hours. As a result of this exposure the reflectivity was lowered only about 2 per cent (see fig. 1). Aluminum is thus found comparable to chromium ${ }^{6}$ in its resistance to corrosion by ultra-violet light. This may not be true of aluminum powder applied with a lacquer.?

\section{DURALUMIN}

Data on the ultra-violet reflecting power of dualumin were given in a previous paper. ${ }^{8}$ The sample was optically flat but had a poor polish, which scattered the incident radiation.

The present sample was composed of a pile of plates (each $1.6 \mathrm{~mm}$ in thickness) clamped together and polished on the edges. As a result the spacing between the plates reduced the total area of the reflecting surface, perhaps, by 10 per cent. This means that the values of all

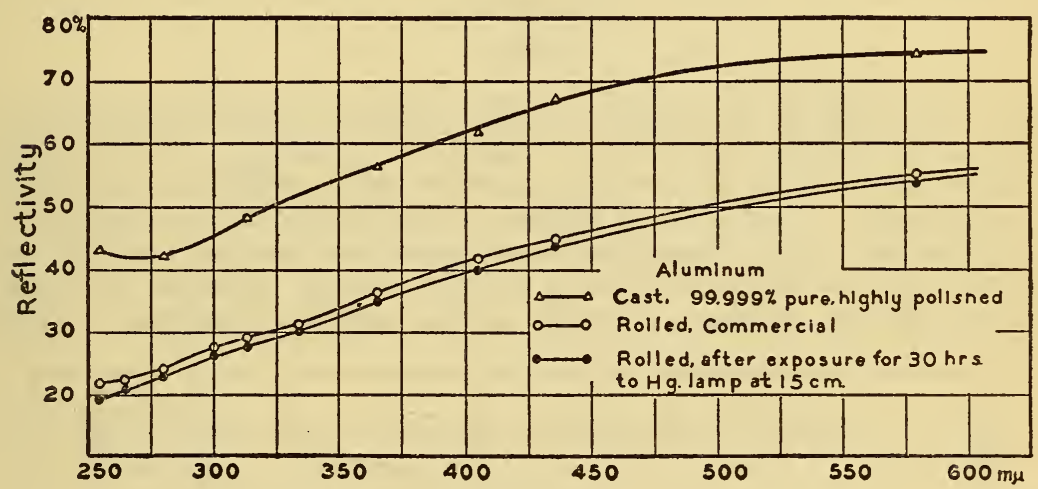

FIgURE 1

the observations should be increased by this amount. The reflecting surface was highly polished (by buffing), but it was not optically flat. The spectral reflection curve (fig. 2) is closely the same as previously observed.

The absolute values in both cases would be, perhaps, 5 to 10 per cent higher than illustrated, owing (1) to the scattering in the sample previously examined, and (2) to the discontinuity in the laminations in the sample examined in the present investigation.

\section{RHODIUM}

The sample examined was a large regulus of the pure material prepared by W. H. Swanger by melting on lime with an oxyhydrogen flame. Originally the surface was optically flat, but did not have a high polish. Subsequently the surface was buffed. The ultra-violet

${ }^{6}$ Coblentz and Stair, B. S. Jour. Research (RP39), 2, p. 343; 1929.

7 Coblentz and Kahler, B. S. Sci. Paper No. 342, 15, p. 215; 1919.

8 Ooblentz and Hughes, B. S. Sci. Papers No. 493, 19, p. 577; 1924. $88500^{\circ}-30-2$ 
spectral reflection of this surface is depicted in Figure 2. The reflecting power rises from 30 per cent at $260 \mathrm{~m} \mu$ to 45 per cent at $365 \mathrm{~m} \mu$. From this point to $580 \mathrm{~m} \mu$ the reflectivity rises slowly to about 46 per cent. No doubt all the values should be corrected for scattering. In the infra-red the reflecting power of rhodium rises to 90 per cent. ${ }^{9}$

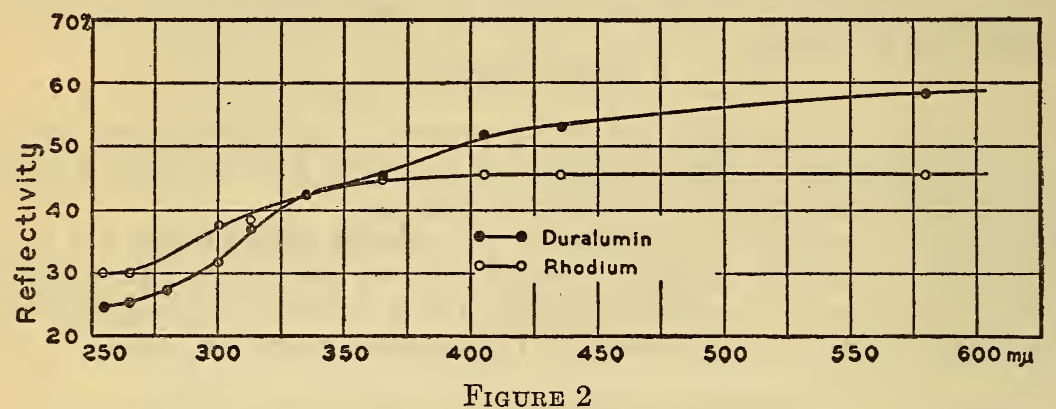

4. TIN

It is very difficult to obtain a highly polished surface on pure tin; moreover the surface tarnishes easily after polishing. The sample examined was a block of the cast pure material, polished and buffed by S. Epstein. As shown in Figure 3, the ultra-violet reflection of tin is relatively high, increasing from about 40 per cent at $300 \mathrm{~m} \mu$ to about 70 per cent at $550 \mathrm{~m} \mu$ for the freshly polished material. The reflectivity decreases rapidly as the surface tarnishes. After

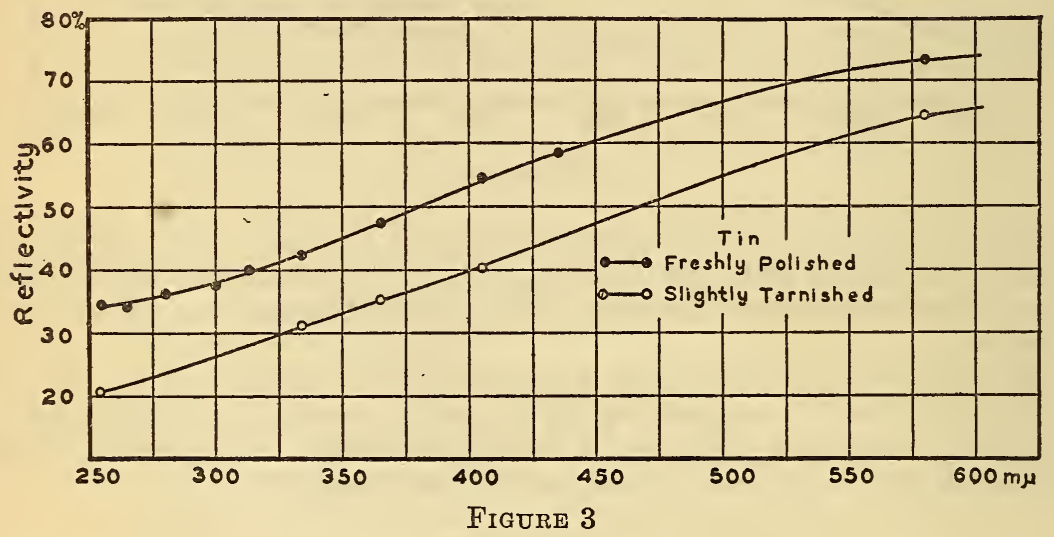

standing in the laboratory over night following the first series of observations the sample was reexamined and found to have undergone a marked decrease in reflectivity. (See fig. 3.)

\section{SUMMARY}

Data are given on the ultra-violet spectral reflection of aluminum, duralumin, rhodium, and tin.

The data obtained on a block of pure material indicate that the ultra-violet reflecting power of aluminum is relatively high, amounting

9 Coblentz, B. S. Bull., No. 152, 7, p. 213; 1910. 
to almost 50 per cent at $300 \mathrm{~m} \mu$ and gradually increasing to 75 per cent at $550 \mathrm{~m} \mu$ in the visible spectrum. The spectral reflection curve of the commercial rolled material is similar in trend to that of the cast block. Aluminum is therefore suitable for an inexpensive reflector of ultra-violet rays, where a correctly figured highly polished surface is not essential.

The ultra-violet spectral reflection of duralumin is similar to that of aluminum.

The reflecting power of rhodium rises rapidly from 30 per cent at $260 \mathrm{~m} \mu$ to 45 per cent at $365 \mathrm{~m} \mu$, beyond which point the rise is more gradual.

Tin has a fairly high reflectivity in the ultra-violet, but deteriorates rapidly by tarnishing.

Washington, August 7, 1929. 